\title{
Upper gastrointestinal surgeon attitudes towards management of refractory gastroesophageal reflux disease in obese patients
}

\author{
Waleed Al-Khyatt, Sherif Awad, Paul Leeder \\ The East-Midlands Bariatric \& Metabolic Institute, Royal Derby Hospital, Derby DE22 3NE, UK. \\ Correspondence to: Dr. Waleed Al-Khyatt, The East-Midlands Bariatric \& Metabolic Institute, Royal Derby Hospital, Uttoxeter Road, \\ Derby DE22 3NE, UK. E-mail: walkhyatt@yahoo.com \begin{abstract}
gastroesophageal reflux disease in obese patients. Mini-invasive Surg 2018;2:3. http://dx.doi.org/10.20517/2574-1225.2017.49
\end{abstract} \\ How to cite this article: Al-Khyatt W, Awad S, Leeder P. Upper gastrointestinal surgeon attitudes towards management of refractory
}

Received: 6 Dec 2017 First Decision: 26 Jan 2018 Revised: 26 Feb 2018 Accepted: 27 Feb 2018 Published: 28 Feb 2018

Science Editor: Charles F. Bellows Copy Editor: Jun-Yao Li Production Editor: Huan-Liang Wu

\begin{abstract}
Aim: The marked increase in prevalence of obesity has been associated with an increase in obese patients seeking surgical treatment for refractory gastroesophageal reflux disease (GORD). The management of GORD in such patients remains contentious with no published guidelines.
\end{abstract}

Methods: A snapshot 9-item online survey was undertaken to elicit professional opinions of UK surgeons regarding the surgical management of refractory GORD in obese patients.

Results: Eighty-two percent and 51\% of surgeons performed more than 10 anti-reflux procedures and more than 10 bariatric procedures per year, respectively. Nearly 80 of responders would consider laparoscopic fundoplication as the preferred option for management of refractory GORD in patients with body mass index (BMI) of $30-34.9 \mathrm{~kg} / \mathrm{m}^{2}$. In contrast, $58 \%$ and $80 \%$ would discuss bariatric surgery as an alternative treatment option for refractory GORD in patients with BMI 35-39.9 and $\geq 40 \mathrm{~kg} / \mathrm{m}^{2}$, respectively. Moreover, a bariatric procedure was considered the preferred option by $74 \%$ of respondents for patients with $\mathrm{BMI} \geq 40 \mathrm{~kg} / \mathrm{m}^{2}$ with refractory $\mathrm{GORD}$, and by $58 \%$ for $\mathrm{BMI} \geq 35$ patients with refractory GORD and significant comorbidities. Eighty percent of surgeons agreed that laparoscopic Roux en-Y gastric bypass (LRYGB) was the preferred bariatric procedure for the management of obese patients with documented GORD.

Conclusion: Our survey demonstrated that amongst UK upper gastrointestinal surgeons, bariatric surgery, specifically LRYGB, was a preferred option for management of patients with a BMI $\geq 35 \mathrm{~kg} / \mathrm{m}^{2}$ and refractory GORD. Updated national guidelines are necessary to inform consensus on the management of GORD in obese patients.

Keywords: Obesity, morbid, bariatric, surgery, gastrooesophageal, reflux

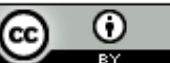

(C) The Author(s) 2018. Open Access This article is licensed under a Creative Commons Attribution 4.0 International License (https://creativecommons.org/licenses/by/4.0/), which permits unrestricted use sharing, adaptation, distribution and reproduction in any medium or format, for any purpose, even commercially, as long as you give appropriate credit to the original author(s) and the source, provide a link to the Creative Commons license, and indicate if changes were made. 


\section{INTRODUCTION}

Gastroesophageal reflux disease (GORD) is defined as a group of symptoms and/or mucosal injury that occurs as a result of reflux of gastric contents into the oesophagus ${ }^{[1]}$. It is a frequently encountered and costly medical condition with an estimated annual cost of proton pump inhibitor use of nearly $£ 500$ million in England alone. The prevalence of GORD and obesity [body mass index (BMI) $>30 \mathrm{~kg} / \mathrm{m}^{2}$ ] has increased significantly over the past three decades in the USA and Europe ${ }^{[2-6]}$. GORD is widely prevalent in obese patients; with increasing BMI considered a risk factor for developing the disease ${ }^{[7-16]}$. The marked increase in prevalence of obesity has been associated with an increase in obese patients seeking surgical treatment for refractory GORD ${ }^{[17]}$. The management of GORD in obese patients remains contentious with no consensus or published guidelines. Data are conflicting regarding the long-term efficacy of fundoplication in obese individuals compared with normal weight counterparts ${ }^{[18-22]}$. Nevertheless, most surgeons would agree that treatment of GORD in obese and non-obese patients requires different strategies ${ }^{[23]}$. The aim of this study was to elicit professional opinions of upper gastrointestinal (GI) surgeons towards the management of refractory GORD in obese patients.

\section{METHODS}

A snapshot 9-item online survey was undertaken between October and November 2015. Members of two UK specialist associations [Association of Upper GI Surgeons (AUGIS) and British Obesity and Metabolic Surgery Society (BOMSS)] were contacted via email and invited to participate in the survey [Supplementary Figure 1]. The questions were designed to characterize training and practice characteristics, experience, and subspecialty interest of respondents. Professional opinions were sought, regarding the optimal treatment for obese patients of varying BMI with medically refractory GORD and reasons for treatment choices.

\section{RESULTS}

A total of 451 specialist association members were emailed the link to the survey questions. All respondents were upper GI surgeons, of whom 51\% were also bariatric surgeons. There was an even distribution of duration of practice as consultant surgeon amongst respondents $(33 \%<5$ years, $27 \%$ had $5-10$ years, 33\% had 11-20 years, and 7\% had $>20$ years experience as consultant). Eighty-two percent regularly performed $\geq 10$ laparoscopic and/or anti-reflux procedures per year and 51\% admitted to regularly performing $\geq 10$ bariatric procedures per year.

Sixty-one surgeons (79\%) considered laparoscopic fundoplication the preferred option for management of refractory GORD in patients with BMI $30-34.9 \mathrm{~kg} / \mathrm{m}^{2}$ [Figure $1 \mathrm{~A}$ ]. However, only $21 \%$ and $11 \%$ would consider laparoscopic fundoplication as their preferred option for BMI 35-39.9 and $\geq 40 \mathrm{~kg} / \mathrm{m}^{2}$, respectively [Figure 1A]. Twenty-one surgeons (20\%) considered anti-reflux surgery not a preferred option for refractory GORD in obese patients. Fifty-eight percent and $80 \%$ would discuss bariatric surgery as an alternative treatment option for refractory GORD in BMI $35-39.9$ and $\geq 40 \mathrm{~kg} / \mathrm{m}^{2}$, respectively [Figure $1 \mathrm{~B}$ ]. Moreover, $74 \%$ and $58 \%$ of respondents considered a bariatric procedure the preferred option in patients, respectively, with $\mathrm{BMI} \geq 40 \mathrm{~kg} / \mathrm{m}^{2}$ with refractory GORD, or BMI $\geq 35 \mathrm{~kg} / \mathrm{m}^{2}$ with significant comorbidities together with refractory GORD [Figure 1C]. Eighty percent of surgeons agreed laparoscopic Roux en-Y gastric bypass (LRYGB) was the bariatric procedure of choice for the management of obese patients with documented GORD [Figure 1D]. Reasons for bariatric surgery not being offered included lack of level one evidence (15\%), lack of national consensus (26\%), difficulty in referring patients for bariatric surgery (12\%) or patient attitudes towards bariatric surgery (16\%).

\section{DISCUSSION}

This snapshot survey sought to elicit UK upper GI surgeon attitudes towards the management of refractory GORD in obese patients. It demonstrated that upper GI surgeons still preferred fundoplication in patients with BMI $30-35 \mathrm{~kg} / \mathrm{m}^{2}$. However, they were less likely to offer fundoplication to patients at higher BMI. The 

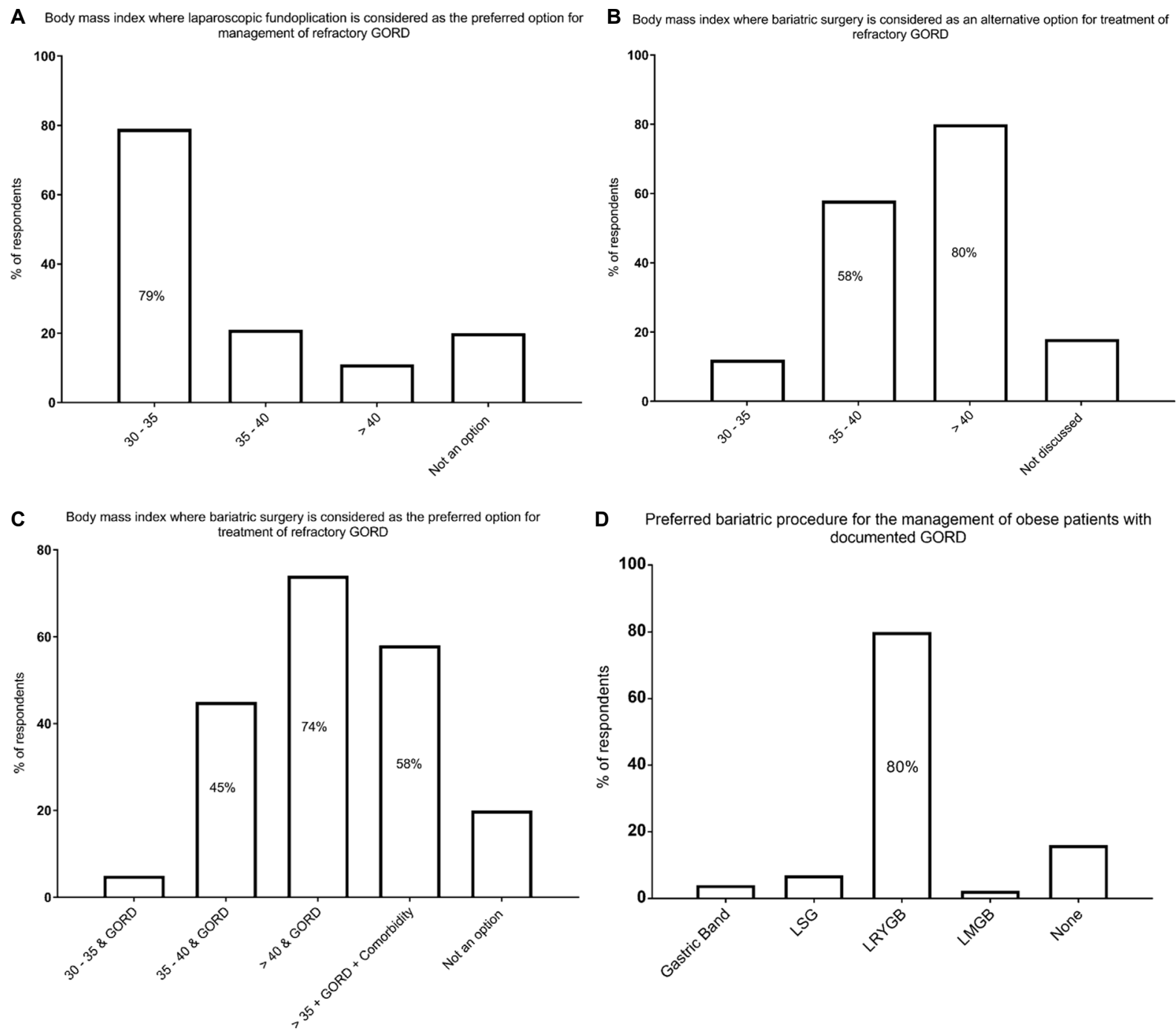

Figure 1. Summary of UK upper gastrointestinal surgeon attitudes towards management of refractory gastroesophageal reflux disease in obese patients. BMI: body mass index; GORD: gastroesophageal reflux disease; LSG: laparoscopic sleeve gastrectomy; LRYGB: laparoscopic Roux en-Y gastric bypass; LMGB: laparoscopic mini gastric bypass

majority of surgeons would consider a bariatric procedure the preferred option for management of refractory GORD in the morbidly obese and would discuss this as an option with their patients. The majority of respondents felt that LRYGB was the best option to treat medically refractory GORD in this patient group.

Anti-reflux surgery is recognised as the treatment option of choice for medically refractory GORD ${ }^{[24-26]}$. However, patient selection is essential to achieving a good outcome $e^{[27]}$. To date, few studies have examined the long-term efficacy and durability of traditional anti-reflux procedures such as Nissen fundoplication in the setting of severe obesity, and results have been conflicting ${ }^{[18-22]}$. It has been suggested that laparoscopic anti-reflux surgery is associated with a higher failure rate in obese patients because of intraoperative technical difficulties as well as increased intra-abdominal pressure postoperatively ${ }^{[28]}$. Nevertheless, others have reported equivalent outcomes in obese and normal weight individuals ${ }^{[17]}$. Obesity and GORD have a well-defined association due to several anatomic and hormonal pathophysiologic mechanisms ${ }^{[7-16]}$. Ultimately, while the medical and surgical treatment of GORD is advancing, there is a relative lack of specific studies examining novel GORD treatments in obese patients.

Existing data demonstrate LRYGB to be associated with significant improvement in GORD symptoms ${ }^{[26,27,29]}$. Many morbidly obese patients with GORD also suffer additional obesity-related conditions that are 
improved by LRYGB. For these reasons, most experts consider LRYGB a better treatment modality than traditional anti-reflux surgery in managing GORD as it also treats underlying obesity and associated comorbidities $^{[26,27,29]}$. The benefits of LRYGB in BMI $<30 \mathrm{~kg} / \mathrm{m}^{2}$ patients is less clear and needs further study ${ }^{[26,27,29]}$.

In this survey, the attitudes of UK surgeons was consistent with previous published international studies ${ }^{[27]}$. In a similar online survey by Pagé et al. ${ }^{[27]}$ who examined the opinions of Members of the Society of American Gastrointestinal and Endoscopic Surgeons (SAGES) regarding the management of GORD in the setting of obesity, most surgeons would offer laparoscopic anti-reflux surgery for patients with BMI $<35 \mathrm{~kg} / \mathrm{m}^{2}$ and symptomatic GORD, while LRYGB was considered the procedure of choice for those patients with BMI $>35 \mathrm{~kg} / \mathrm{m}^{2[27]}$. However, Pagé et al. ${ }^{[27]}$ suggest that morbidly obese patients with GORD, who would otherwise be best served with LRYGB, actually underwent Nissen fundoplication or no procedure at all due to financial limitations and policy exclusions. In contrast, UK surgeons would not consider bariatric surgery as their choice mainly due to the lack of national consensus and guidelines. Restrictions in commissioning in the UK may also have an impact if a significant number of patients were to undergo bariatric surgery primarily to manage reflux. The results of this survey may help inform surgeon practices pending development of much needed national consensus guidelines.

Limitations of this study include an $18 \%$ response rate, and that the opinions of specialty associations may not be representative of the wider UK surgical community. Finally, this study was designed to elicit surgeon opinions and attitudes and was not a randomised study comparing the two approaches.

In conclusion, this survey demonstrated bariatric surgery, specifically LRYGB, to be considered the preferred treatment option for BMI $\geq 35 \mathrm{~kg} / \mathrm{m}^{2}$ patients with refractory GORD. There is a need for published national guidance to inform clinical practice on the management of GORD in patients with severe and complex obesity.

\section{DECLARATIONS}

\section{Authors' contributions}

Manuscript preparation and data acquisition: Al-Khyatt W, Awad S, Leeder P

Data analysis and parasitological classification: Al-Khyatt W

Literature search: Al-Khyatt W

Data acquisition: Al-Khyatt W

Anatomopathological classification: Al-Khyatt W, Awad S, Leeder P

Study design and definition of intellectual content: Al-Khyatt W, Awad S, Leeder P

\section{Data source and availability}

All data are stored in a password protected hard drive and available on request via the corresponding author.

\section{Financial support and sponsorship}

Sherif Awad has received unrestricted educational and travel grants from Fresenius Kabi, Nestle Nutrition, Medtronic, Ethicon EndoSurgery, Merck Sharp \&Dohme, Fischer \&Paykel Healthcare Ltd, and BBraun. He has received honoraria and consultancy fees from Apollo Endosurgery, Merck Sharp \&Dohme and Fischer \&Paykel Healthcare Ltd. He has also completed a bariatric fellowship funded via an educational grant from Ethicon EndoSurgery (paid to the institution). Paul Leeder has received unrestricted educational grants from Ethicon, Medtronic and Allergan. He has received honoraria from Karl Storz and Allergan.

\section{Conflicts of interest}

The authors have no direct conflicts of interest to declare. 


\section{Patient consent}

Not applicable.

\section{Ethics approval}

Not applicable.

\section{Copyright}

(c) The Author(s) 2018.

\section{REFERENCES}

1. Vakil N, van Zanten SV, Kahrilas P, Dent J, Jones R. The montreal definition and classification of gastroesophageal reflux disease: a global evidence-based consensus. Am J Gastroenterol 2006;101:1900-20.

2. Dent J, El-Serag HB, Wallander MA, Johansson S. Epidemiology of gastro-oesophageal reflux disease: a systematic review. Gut 2005;54:710-7.

3. El-Serag HB, Sweet S, Winchester CC, Dent J. Update on the epidemiology of gastro-oesophageal reflux disease: a systematic review. Gut 2014;63:871-80

4. $\quad$ El-Serag H. Role of obesity in GORD-related disorders. Gut 2008;57:281-4.

5. Lagergren J. Influence of obesity on the risk of esophageal disorders. Nat Rev Gastroenterol Hepatol 2011;8:340-7.

6. El-Serag HB, Graham DY, Satia JA, Rabeneck L. Obesity is an independent risk factor for GERD symptoms and erosive esophagitis. Am J Gastroenterol 2005;100:1243-50.

7. Locke GR 3rd, Talley NJ, Fett SL, Zinsmeister AR, Melton LJ 3rd. Risk factors associated with symptoms of gastroesophageal reflux. Am J Med 1999;106:642-9.

8. Murray L, Johnston B, Lane A, Harvey I, Donovan J, Nair P, Harvey R. Relationship between body mass and gastro-oesophageal reflux symptoms: The Bristol Helicobacter Project. Int J Epidemiol 2003;32:645-50.

9. Ruhl CE, Everhart JE. Overweight, but not high dietary fat intake, increases risk of gastroesophageal reflux disease hospitalization: the NHANES I Epidemiologic Followup Study. First National Health and Nutrition Examination Survey. Ann Epidemiol 1999;9:424-35.

10. Hampel H, Abraham NS, El-Serag HB. Meta-analysis: obesity and the risk for gastroesophageal reflux disease and its complications. Ann Intern Med 2005;143:199-211.

11. Corley DA, Kubo A. Body mass index and gastroesophageal reflux disease: a systematic review and meta-analysis. Am J Gastroenterol 2006;101:2619-28.

12. Crowell MD, Bradley A, Hansel S, Dionisio P, Kim HJ, Decker GA, DiBaise JK, Sharma VK. Obesity is associated with increased 48-h esophageal acid exposure in patients with symptomatic gastroesophageal reflux. Am J Gastroenterol 2009;104:553-9.

13. Singh S, Sharma AN, Murad MH, Buttar NS, El-Serag HB, Katzka DA, Iyer PG. Central adiposity is associated with increased risk of esophageal inflammation, metaplasia, and adenocarcinoma: a systematic review and meta-analysis. Clin Gastroenterol Hepatol 2013;11:1399-412.e7.

14. Pandolfino JE, El-Serag HB, Zhang Q, Shah N, Ghosh SK, Kahrilas PJ. Obesity: a challenge to esophagogastric junction integrity. Gastroenterology 2006;130:639-49.

15. El-Serag HB, Ergun GA, Pandolfino J, Fitzgerald S, Tran T, Kramer JR. Obesity increases oesophageal acid exposure. Gut 2007;56:749-55.

16. Schneider JE, Brücher BDM, Küper M, Saemann K, Königsrainer A, Schneider J. Multichannel intraluminal impedance measurement of gastroesophageal reflux in patients with different stages of morbid obesity. Obes Surg 2009;19:1522-9.

17. Telem DA, Altieri M, Gracia G, Pryor AD. Perioperative outcome of esophageal fundoplication for gastroesophageal reflux disease in obese and morbidly obese patients. Am J Surg 2014;208:163-8.

18. Morgenthal C, Lin E, Shane M, Hunter J, Smith CD. Who will fail laparoscopic Nissen fundoplication? Preoperative prediction of longterm outcomes. Surg Endosc 2007;21:1978-84.

19. Perez AR, Moncure AC, Rattner DW. Obesity adversely affects the outcome of antireflux operations. Surg Endosc 2001;15:986-9.

20. Ng VV, Booth MI, Stratford JJ, Jones L, Sohanpal J, Dehn TC. Laparoscopic anti-reflux surgery is effective in obese patients with gastrooesophageal reflux disease. Ann R Coll Surg Engl 2007;89:696-702.

21. Anvari M, Bamehriz F. Outcome of laparoscopic Nissen fundoplication in patients with body mass index $\geq 35$. Surg Endosc 2006;20:230-4

22. D'Alessio MJ, Arnaoutakis D, Giarelli N, Villadolid DV, Rosemurgy AS. Obesity is not a contraindication to laparoscopic Nissen fundoplication. J Gastrointest Surg 2005;9:949-54.

23. Vakil N, van Zanten SV, Kahrilas P, Dent J, Jones R, Global Consensus G. The Montreal definition and classification of gastroesophageal reflux disease: a global evidence-based consensus. Am J Gastroenterol 2006;101:1900-20; quiz 43.

24. Dallemagne B, Perretta S. Twenty years of laparoscopic fundoplication for GERD. World J Surg 2011;35:1428-35.

25. Katz PO, Gerson LB, Vela MF. Guidelines for the diagnosis and management of gastroesophageal reflux disease. Am J Gastroenterol 2013;108:308-28.

26. Stefanidis D, Hope WW, Kohn GP, Reardon PR, Richardson WS, Fanelli RD. Guidelines for surgical treatment of gastroesophageal reflux disease. Surg Endosc 2010;24:2647-69.

27. Pagé MP, Kastenmeier A, Goldblatt M, Frelich M, Bosler M, Wallace J, Gould J. Medically refractory gastroesophageal reflux disease in the obese: what is the best surgical approach? Surg Endosc 2014;28:1500-4.

28. Morgenthal CB, Lin E, Shane MD, Hunter JG, Smith CD. Who will fail laparoscopic Nissen fundoplication? Preoperative prediction of long-term outcomes. Surg Endosc 2007;21:1978-84.

29. Pallati PK, Shaligram A, Shostrom VK, Oleynikov D, McBride CL, Goede MR. Improvement in gastroesophageal reflux disease symptoms after various bariatric procedures: review of the Bariatric Outcomes Longitudinal Database. Surg Obes Relat Dis 2014;10:502-7. 